Jacques Vauclair Hélène Cochet

Research Center in the Psychology of Cognition, Language \& Emotion Department of Psychology, Aix-Marseille University, 29, av. Robert Schuman 13621 Aix-en-Provence Cedex 1, France E-mail: jacques.vauclair@univ-amu.fr

\section{Hand Preference for Pointing and Language Development in Toddlers}

\begin{abstract}
The aim of this study was to investigate the relationship between hand preference for communicative gestures and language during development. Hand preference for pointing gestures and level of language were assessed in 46 toddlers between 12 and 30 months of age. Results showed a right-hand preference for pointing and the use of a developmental quotient (DQ) for language revealed a significant correlation between the degree of hand preference and $D Q$ for language in children with a quotient above 100. Thus, these children were more right-handed for pointing gestures as $D Q$ increased. These results highlight the close association between the development of hand preference for pointing and the speed of language development, suggesting a new direction for studies of language-gesture links in toddlers. (C) 2012 Wiley Periodicals, Inc. Dev Psychobiol 55: 757-765, 2013.
\end{abstract}

Keywords: communication development; pointing gestures; language; hemispheric specialization; toddlers; developmental quotient

\section{INTRODUCTION}

The coupling between language and gestures has been highlighted on several levels, from neuropsychological and neuroanatomical studies in adults to developmental studies reporting the importance of communicative gestures for language development in young children (Bates \& Dick, 2002; Iverson \& Thelen, 1999, for review). Considering the left-hemispheric specialization for language in humans (e.g., Knecht et al., 2000) and the contralateral control of precise movements of hands and fingers, the main objective of the present research was to investigate these language-gesture links focusing on the relation between children's hand preference for pointing gestures and language development.

The end of the first year sees the advent of the first intentional communicative gestures produced within a

\footnotetext{
Manuscript Received: 17 February 2012

Manuscript Accepted: 12 July 2012

Correspondence to: J. Vauclair

Contract grant sponsor: French National Research Agency (ANR)

Contract grant number: ANR-08-BLAN-0011_01

Article first published online in Wiley Online Library

(wileyonlinelibrary.com): 27 August 2012
}

DOI 10.1002/dev.21073 • (c) 2012 Wiley Periodicals, Inc. joint attention framework, which represents an important step in language development (Baldwin et al., 1996; Moll \& Tomasello, 2007; Tomasello, Carpenter, $\&$ Liszkowski, 2007). For example, the use of pointing gesture as a referential and intentional tool develops at around 11 months of age (Butterworth \& Morissette, 1996). The purpose of pointing is to direct others' attention towards an external object, event or location and several researchers have suggested that the production of pointing gestures was associated with the child's ability to grasp that other people have independent mental states and that these states can be modified (Camaioni, 1997; Franco \& Butterworth, 1996; Liszkowski, Carpenter, Henning, Striano, \& Tomasello, 2004; Liszkowski, Carpenter, \& Tomasello, 2008). These cognitive abilities are of key importance for the emergence of language (see also Heimann et al., 2006), which is one of the reasons advanced to explain the facilitative effect of gestures on language and speech acquisition (e.g., Tomasello, 2008). Indeed, the production of communicative gestures is correlated with language comprehension and production (e.g., Laasko, Poikkeus, Katajamäki, \& Lyytinen, 1999; Rowe \& GoldinMeadow, 2009; Rowe, Özçaliskan, \& Goldin-Meadow, 2008; Volterra, Caselli, Capirci, \& Pizzuto, 2005) and 
the onset of gesture-plus-word combinations conveying two semantic elements in a single proposition was reported to predict the onset of two-word combinations (Iverson \& Goldin-Meadow, 2005). Moreover, the frequency of use of these gesture-plus-word combinations increases during the second year (Özçaliskan \& Goldin-Meadow, 2005), allowing children to enlarge their communicative repertoire and express meanings of increasing complexity.

Second, given the left-hemispheric specialization for language in humans, the investigation of hand preference for communicative gestures can provide further evidence to support the existence of language-gesture links. Several studies with infants and children have reported an asymmetry in favor of the right hand for communicative gestures, pointing in particular, indicating a stronger involvement of the left cerebral hemisphere (Blake, O'Rourke, \& Borzellino, 1994; Cochet \& Vauclair, 2010a; Young, Lock, \& Service, 1985). Interestingly, communicative and symbolic gestures produced by young children lead to stronger righthandedness than other manual actions (Bates, O'Connell, Vaid, Sledge, \& Oakes, 1986; Cochet \& Vauclair, 2010b; Vauclair \& Imbault, 2009). Moreover, the strength of manual asymmetry for manipulative activities keeps increasing during early childhood (McManus et al., 1988), but the right-sided bias for a subset of manual activities, namely for pointing and symbolic gestures, appears already formed in earlier stages of development, as it did not seem to vary between approximately 1 and 3 years of age (e.g., Cochet $\&$ Vauclair, 2010c). Hand preference for communicative gestures therefore seems to be established earlier and in a more stable way than handedness for manipulative actions (e.g., Esseily, Jacquet, \& Fagard, 2011).

Another study of children born to deaf parents using sign language revealed greater asymmetry in favor of the right hand for signed gestures than for other manual activities (Bonvillian, Richards, \& Dooley, 1997), again showing that the link between the lateralization of language and manual movements is most obvious for communicative and meaningful gestures. In addition, even though hemispheric specialization for language is likely to increase during childhood (e.g., Ressel, Wilke, Lidzba, Lutzenberger, \& Krägeloh-Mann, 2008), several studies have shown that infants and toddlers already present functional and structural hemispheric asymmetries in speech perception-production networks (e.g., Dehaene-Lambertz, Dehaene \& Hertz-Pannier, 2002; Dubois et al., 2009; Mills, Coffey-Corina, \& Neville, 1993).

Altogether, these findings suggest an early association between the cerebral control of language and communicative gestures, which has led researchers to postulate the existence of a specific communication system in the left cerebral hemisphere, controlling both gestural and vocal communication (e.g., Gentilucci \& Dalla Volta, 2008; Xu, Gannon, Emmorey, Smith, \& Braun, 2009). Furthermore, the different patterns of hand preference between communicative gestures and manipulative actions suggest that this communication system may differ from the system involved in purely motor activities.

These specific links between speech and gesture could be explained in the light of the gestural hypothesis for the origin of language (e.g., Corballis, 2003, 2010; Hewes, 1973). According to this hypothesis, gestures constituted the first intentional means of communication for early Hominids. Lateralization of language evolved from this left-lateralized gestural system and, in the course of evolution, the vocal modality gradually became dominant. This hypothesis is supported by behavioral and neuroanatomical studies of non-human primates, which have notably reported stronger degrees of right-sided asymmetry for communicative behaviors compared to manipulative actions (e.g., Meguerditchian \& Vauclair, 2009; Meguerditchian, Vauclair, \& Hopkins, 2010; Taglialatela, Cantalupo, \& Hopkins, 2006).

The aim of the present study was to investigate the relationship between the development of language and hand preference for gestural communication, through the case of pointing gestures, in infants and toddlers. These two measures (hand preference for pointing and language development) may provide indexes, though indirect, of cerebral processes involved in early communication and thus contribute to clarify the nature of language-gesture links. Most of the time, research on the asymmetry of communicative gestures in toddlers only takes the age of the participants into account and generally covers short periods. We then set out to study the relationship between language and pointing gestures between the ages of 12 and 30 months, using a reliable and normative language test.

Our first hypothesis was that we would find a rightsided bias for pointing gestures, in line with many previous studies. Based on the assumption that communicative gestures and language are mediated by common neural systems (e.g., Xu et al., 2009), our second hypothesis was that changes in hand preference for pointing would be related to the dynamics of language acquisition. Imaging studies with school-age children have reported that changes in cerebral activity, which parallel learning-related changes traced by fMRI in adults, were related to experience-driven maturational processes: the amplitude of activation increases in taskrelevant brain regions, whereas activation attenuates in areas not critically involved in specific task (Casey, 
Tottenham, Liston, \& Durston, 2005). Moreover, developmental changes in the patterns of cerebral activity have already been suggested to be associated with behavioral performance measures (e.g., Durston et al., 2006). Mills et al. (1993) for example examined neural activity associated with language processing using event-related potentials (ERP) in 20-month-old infants. Differences have been observed in ERP components between low and high language producers over parietal and temporal regions of the left cerebral hemisphere, reflecting an association between increasing levels of language abilities and increasing cerebral specialization for language processing.

Therefore, we hypothesized that hand preference for pointing gestures would be linked to language learning rate over development, assessed for each child via a developmental quotient (DQ) for language. A relatively fast development of language, compared to the population of reference at the same age, was thus expected to be linked to a greater right-sided bias for communicative gestures, through higher activation of the communication system in the left cerebral hemisphere. In other words, communicative gestures may be more right-handed in children with high language learning abilities compared to other children.

\section{METHOD}

\section{Participants}

Forty-six French toddlers and young children (23 girls and 23 boys) between 12 and 30 months of age were recruited in daycare centers. Their average age was 22 months and 15 days ( $S D=5$ months and 6 days). Parents' socio-economic status was assessed based on their occupation and level of education: 18 children were from upper-middle-class families, 21 from lower-middle-class families, and 7 from workingclass families. Thirty-five children were first-born and 11 were second- or third-born. The study took place in their homes, in the room where they were used to playing and interacting with their parents.

\section{Material}

To assess language comprehension and production, the "language" subtest of the widely used Brunet-Lézine scale (1965), revised by Josse (1997), was used. ${ }^{1}$ This scale is designed to assess psychomotor development in infants and toddlers (between 2 and 30 months of age). The language subtest comprises a task in which children have to point to

\footnotetext{
${ }^{1}$ The "language" subtest of the Brunet-Lézine scale is comparable to the Peabody Picture Vocabulary Test (PPVT), insofar as both tests are normreferenced and assess children's linguistic skills, via pictures of familiar objects. Nevertheless, the PPVT is not designed for children younger than 2 years old and only focuses on individual's receptive vocabulary.
}

and name familiar objects $(N=10$, including for example a spoon, a pencil, and a pair of glasses) and pictures $(N=15$, including for example, a banana, a house, and a bike). Participants either directly name the different items or indicate the location of the objects and pictures designated by the experimenter when they are too young to produce the corresponding words (in the latter case, children had to point to a specific picture among either six or nine different pictures, depending on their age). This language test is organized into 17 items, including 9 items that are based on parental reports, when behaviors cannot be directly observed (e.g., knowing whether children use their first name when talking about themselves). A raw score is obtained; the maximum possible score is 73 , obtained when all the items have been successfully completed. From this raw score, it is possible to infer a developmental age for language via the French norms provided by the revised scale. Dividing the developmental age by the chronological age yields a DQ for language.

\section{Procedure}

After a few minutes of warm-up period, the language test and two pointing tasks were presented. The order of these tasks (language test and pointing tasks) was alternated across participants. All sessions were videotaped.

Language Assessment. For the Brunet-Lézine test, the child was seated either at a table (child-size furniture was used) or on the mother's lap. The experimenter was seated in front of the participant and showed him/her the different objects and pictures one at a time.

Pointing Tasks. Two pointing tasks were presented in an alternating order across participants. Children were tested in conditions that were similar to those used for the language assessment. In the first task, children were asked to point to different pictures (e.g., a dog, a ball) in a children's book positioned on the table in front of them. It was the page and not the book that was placed on the table in order to avoid any bias due to visual field dependence (i.e., young participants tend to point to a character on the right page with their right hand and on the left page with their left hand: Butterworth, Franco, McKenzie, Graupner, \& Todd, 2002). Four trials were administered. In the second task, children had to point to toys (e.g., stuffed animal, light-up toy) in the immediate environment, approximately 1-2 $\mathrm{m}$ away from them. The experimenter asked the children about the location of a specific toy, after ensuring that it was positioned in front of them, at the center of their visual field. Four trials were again administered. For each trial, data were only recorded when children were sitting in a symmetrical posture, with both hands initially free.

\section{Data Analyses}

An individual Handedness Index score (HI) was calculated for each participant using the formula $(R-L) /(R+L)$, where $R$ and $L$ stand for the total right- and left-hand responses, respectively. The HI values lay along a continuum 
from -1 to 1 , with the sign indicating hand-preference direction and the absolute value reflecting hand-preference strength. Participants were classified as having a right-hand preference for pointing if they performed at least six of the eight trials with the right hand ( $\mathrm{HI} \geq .5$ ), as having a lefthand preference if they performed at least six of the eight trials with the left hand $(\mathrm{HI} \leq-.5)$ and as ambidextrous, namely, as having no preference for pointing, if $\mathrm{HI}$ varied between -.5 and .5 .

\section{RESULTS}

\section{Hand Preference for Pointing Gestures}

Individual $\mathrm{HI}$ for pointing gestures ranged from -.5 to 1 . Mean HI was $.52(S D=.39)$. Thirty participants $(65 \%)$ were classified as right-handers, $1(2 \%)$ as a lefthander, and $15(33 \%)$ as ambidextrous. Thus, among the 31 lateralized participants, $97 \%$ had a right-hand preference for pointing. Results did not reveal any significant correlation between age and $\mathrm{HI}$ for pointing gestures $(r=-.13$; n.s. $)$.

\section{Language Development}

Language test scores varied between 18 and 73. The mean score was $50.4(S D=19.8)$. DQ for language varied between 71.8 and $131.2(M=100.8 ; S D=$ 13.5). Analysis of the results indicated a significant correlation between age and the score on the language test: $r=.87, p<.001$ (see Fig. 1 ), thus confirming the reliability and validity of the Brunet-Lézine scale.

\section{Hand Preference for Pointing Gestures and Language Development}

As the Brunet-Lézine scale does not provide any direct correspondence between raw scores and specific steps

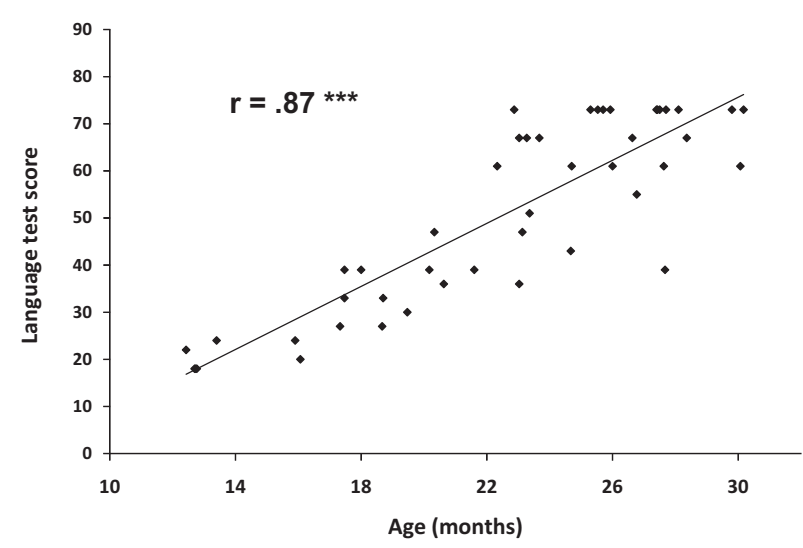

FIGURE 1 Scatter plots displaying the relationship between age and language scores. in language acquisition (i.e., the lexical spurt for example is not associated with a specific score range), we only performed analyzes based on the DQ. The latter reflects the rate of language acquisition, in comparison with the population of reference at the same age. It is obtained by dividing the developmental age (based on the Brunet-Lézine normative scores) by the children's chronological age and by multiplying the value by 100 . When the developmental age is equivalent to the chronological age, the quotient is thus 100 . In addition, given that HI are skewed towards positive values, we used non-parametric tests to investigate the relationship between hand preference for pointing and DQ for language, including Spearman's rank correlations and Mann-Whitney's $U$-tests.

There was no significant correlation between $\mathrm{HI}$ for pointing and DQ for language, $r=-.20$; n.s., $N=46$. However, the scatter plot examining the relation between HI for pointing gestures and DQ for language suggested the existence of a nonlinear and categorical relation between these two variables (see hereafter).

For further analyses, we distinguished between children with a DQ below 100 (Group 1, $M=89.25$; $S D=7.29 ; N=22$ ), who were relatively less proficient for their age and children with a DQ above 100 (Group 2, $M=111.96 ; S D=7.53 ; N=23$ ), whose linguistic abilities could be considered as relatively advanced for their age. Mean ages of the Group 1 $(M=21$ months and 15 days; $S D=5$ months and 19 days) and of the Group 2 ( $M=23$ months and 9 days; $S D=4$ months and 23 days) did not significantly differ, $t(45)=1.16$; n.s. In Group 1 , HI for pointing gestures was negatively correlated with DQ for language, $r=-.44 ; p<.05$ (see Fig. 2), whereas we found a

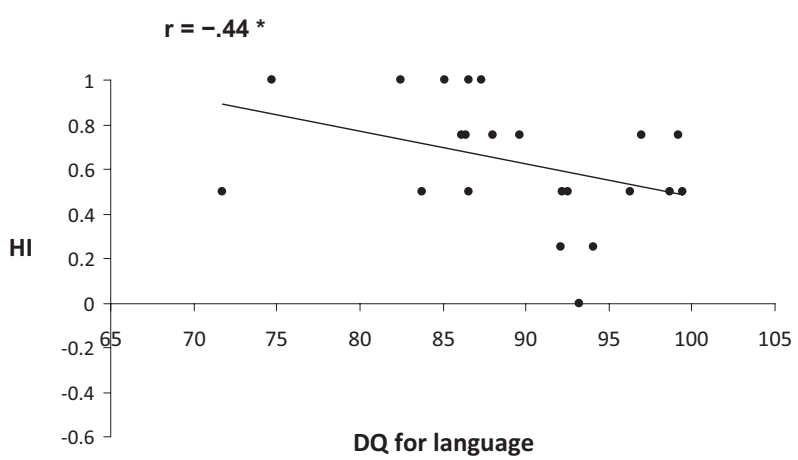

FIGURE 2 Negative relationship between developmental quotient (DQ) for language and Handedness Index (HI) for pointing in Group 1 (DQ $<100$, low language users). HI can vary between -1 and 1 ; the sign indicates the direction of hand preference (a positive sign indicates a right-hand preference) and the absolute values reflect the strength of hand preference. 
significant positive correlation between HI and DQ in Group 2, $r=.55 ; p<.01$ (see Fig. 3).

Moreover, Mann-Whitney's $U$-test revealed that pointing gestures tended to be more right-handed in Group $1(M=.63 ; S D=.28)$ than in Group $2(M=$ $.39 ; S D=.45), Z=1.85, p=.064$. However, this was due to the presence of the left-handed participant in Group 2, since the difference in mean HI was no longer significant after excluding this participant (in Group 2: $M=.43 ; S D=.42), Z=1.65$, n.s. The correlation between HI for pointing and DQ in Group 2 was still significant without the left-handed participant, $r=.49$; $p<.05$.

To summarize, significant effects were observed when participants were divided into two different groups, according to their low or high DQ for language. In children with a DQ above 100 , pointing gestures were found to be more right-handed as DQ increases. By contrast, this relationship between HI and DQ was not observed in children with a DQ below 100, and was even reversed, that is, pointing gestures were less right-handed as DQ increases.

It should be mentioned that one participant, whose DQ was equal to 100 , was excluded from the previous analyses as we had no reason to include him into one group rather than in the other. When including this participant in Group 1, the negative correlation between HI for pointing and DQ was not significant, $r=-.30$; n.s. When including the participant in Group 2, the positive correlation between $\mathrm{HI}$ for pointing and DQ tended to be significant, $r=.39 ; p=.061$.

Finally, the effects of different variables (gender, birth order, family context: children living with only one parent vs. both parents, parents' socioprofessional category and parents' handedness) were assessed using an analysis of variance with $\mathrm{HI}$ score and language level serving as the dependent measures. We did not

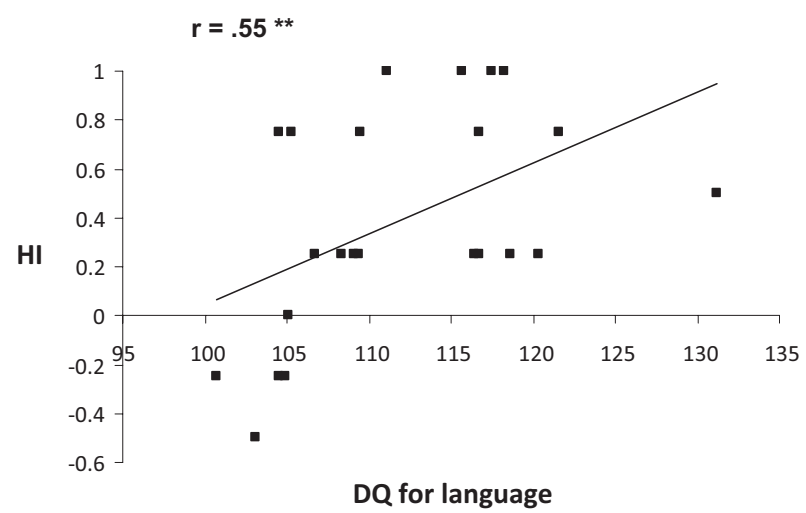

FIGURE 3 Positive relationship between developmental quotient (DQ) for language and Handedness Index (HI) for pointing in Group 2 (DQ $>100$, high language users). observe any effect of gender on either the Handedness Index scores $(F(1,44)=.31$; n.s. $)$, the language test scores $(F(1,44)=.33 ;$ n.s. $)$ or the DQ $(F(1$, $44)=1.53$; n.s.). We then assessed the potential effect of birth order. The first-born children's mean HI score was .49 versus .58 for the other children, but this difference did not reach statistical significance $(F(1$, $44)=.37$; n.s.). We did not observe any effect of birth order either on language scores $(F(1,44)=1.22$; n.s.) or on the DQ $(F(1,44)=1.23$; n.s.). The effect of family context could not be tested because only four children were from a single-parent family. Some group sizes were also too small for us to test the potential effect of parents' socioprofessional category (e.g., only seven children had working-class parents).

\section{DISCUSSION}

Behavioral measures can provide insights into cerebral activities involved in communication during development and thus contribute to clarify the nature of language-gesture links. The present study focused on hand preference for pointing gestures and sought to investigate the relationships between hand preference and language acquisition in toddlers.

First, our results revealed a right-sided bias for pointing gestures. The Mean Handedness Index (MHI) was .52, which is similar to the results of Vauclair and Imbault (2009) with children between 10 and 40 months of age and to those of Esseily et al. (2011) with toddlers between 14 and 20 months of age. Thus, the present study shows that gestural communication preferentially involves the right hand and therefore the left cerebral hemisphere, confirming the results of several previous studies (e.g., Bates et al., 1986; Blake et al., 1994; Bonvillian et al., 1997; Cochet \& Vauclair, 2010a,b; Young et al., 1985). Our results did not reveal any increase in the right-sided bias between 12 and 30 months of age, in line with other studies of hand preference for pointing over similar age ranges (Bates et al., 1986; Jacquet, Esseily, Rider, \& Fagard, 2012). In fact, authors who have reported an increase in the right-hand preference were either interested in manipulative actions (e.g., Fagard \& Marks, 2000) or studied participants who were younger than those involved in our study (e.g., Blake et al., 1994; Young et al., 1985). Young et al. (1985), for instance, reported an increase in the right-sided bias for pointing gestures between 8 and 15 months of age. But in the present study, the youngest participants (between 12 and 15 months of age) were already strongly right-handed, making a subsequent increase in the right-sided bias unlikely. Our results then emphasized that infants exhibit 
asymmetries in communication processes in the early stages of intentional gestural communication, and before speech comes to carry the main burden of communication (Trevarthen, 1996).

Second, we investigated the relation between language and hand preference for pointing gestures. The establishment of a DQ using the Brunet-Lézine scale revealed a complex relationship between hand preference for pointing gestures and the rate of language development. In children with a DQ above 100 (Group 2 ), the asymmetry of pointing gestures was found to strengthen as DQ increases, whereas in children with a DQ below 100 (Group 1), pointing gestures became less right-handed as DQ increases.

This distinction between relatively high and low language users (i.e., in relation to the language norms at each age) may be associated with different patterns of cerebral activity in the left hemisphere. Children with a high DQ developed linguistic abilities relatively faster than other children, which is likely to involve greater left-hemisphere activity. Although it involved only 20month-old children, an ERP study had already highlighted the importance of speech rate acquisition in the emergence of hemispheric specialization (Mills, Plunkett, Prat, \& Schafer, 2005). As expected, our results revealed that this high level of cerebral and cognitive resources required for language was linked to a stronger right-handed bias for pointing gestures, thus supporting the existence of a close relationship between language and communicative gestures.

Findings of the present study are therefore in agreement with the hypothesis that a specific system in the left cerebral hemisphere is specialized for both gestural and linguistic communication. This hypothesis has been strengthened by recent studies investigating the influence of gestures on speech (Gentilucci \& Dalla Volta, 2007 for review). Bernardis and Gentilucci (2006) have shown, for example, that the voice frequency spectrum is higher when a word is pronounced together with the corresponding gesture than when it is pronounced on its own. This effect has not been observed either with a meaningless and arbitrary arm movement or with a pseudo word. This link between the two communicative signals has also been observed in infants when speech is beginning to emerge: manipulating or pointing to large objects rather than small objects leads to an increase in the acoustic properties (F2 formant) of the infants' vocalizations (Bernardis, Bello, Pettenati, Stefanini, \& Gentilucci, 2008). Lastly, there is neural evidence that both types of information are simultaneously integrated by the brain, again emphasizing the close interconnection between speech and gesture (Özyürek, Willems, Kita, \& Hagoort, 2007; Willems \& Hagoort, 2007).
We had hypothesized that gestures would be more right-handed in children with high linguistic ability, but we did not expect to observe a negative relationship between the degree of hand preference for pointing and DQ for language in children with relatively low language quotient. Although the relation between hand preference for pointing and DQ for language reached a weaker significance level in this group (Group 1) compared to the other one (Group 2), direct measures of hemispheric activity would be necessary to explain this unexpected result. Indeed, we now have to examine directly the potential differences in brain activation patterns related to communication processes between children with low and high DQ. Moreover, although the relationship between hand preference for pointing and language acquisition has previously been investigated in toddlers (e.g., Cochet, Jover, \& Vauclair, 2011, Jacquet et al., 2012), the present study is the first of its kind, to our knowledge, to have considered the DQ for language. Consequently, our results need to be replicated and should be interpreted with caution.

Taken as a whole, the relations observed in the present study between hand preference for pointing and language development suggests that changes in hand preferences for communicative gestures are linked to the activity level of the left cerebral hemisphere. The latter is likely to display greater activation if a given child develops linguistic abilities relatively faster than other children, leading to a stronger right-handed bias for pointing gestures. We still need to find out whether the development of hand preference is also related to the type of ability that is developing, that is, to some specific steps in language acquisition (e.g., speech emergence, lexical spurt, first combinations of words). Although some researchers did not find any significant correlation between language level and hand preference for symbolic gestures (Bates et al., 1986), a more recent study has suggested that the lexical spurt was tightly connected with the left-hemisphere specialization for communicative gestures (Cochet et al., 2011). Pointing gestures might thus be more right-handed during these key periods of language development.

Measures of handedness for manipulative actions would have provided an interesting comparison with the patterns of hand preference that were recorded for pointing. However, we decided to focus solely on hand preference for communicative gestures in the present study, as it has already been reported that hand preferences for pointing and for manipulative activities are not correlated (Bates et al., 1986; Cochet, 2012; Cochet \& Vauclair, 2010b). Moreover, the study by Knecht et al. (2000) revealed that $70 \%$ of left-handers had lefthemispheric control for speech, indicating that the 
relationship between handedness for manipulation and speech is, at best, very indirect.

A last issue that needs to be raised concerns the linguistic skills that were assessed by the language subtest of the Brunet-Lézine scale. Most of the items measured lexical development, but there were also some items (based on parental reports) related to syntax development, for example regarding the ability to produce twoword utterances. Moreover, this scale did not allow us to distinguish between comprehension and production of language (e.g., at 20 months of age, one item was coded as successful either when children pointed towards four different pictures of objects or when they named two of them). We cannot exclude the possibility that hand preference for pointing relates in different ways to lexicon and syntax, and/or to comprehension and production of language. These various language components should thus be taken into account in further studies (see Esseily et al., 2011).

To conclude, our findings revealed that right-hand preference for children's pointing gestures is linked to their language skills, more precisely to the speed of speech development. Brain activity is of course driven by multiple and complex mechanisms, including changes in cognitive skills. It appears then quite challenging to unravel these mechanisms using behavioral measures, but the present study has the merit of suggesting new directions for research with toddlers, that is, investigating language-gesture links by focusing on the rate of language acquisition. Moreover, our results are congruent with the existence of a system in the left cerebral hemisphere which would control both gestural and vocal communication. This system appears to be located in Broca's area (Gentilucci \& Dalla Volta, 2007) and may have a deep phylogenetic origin (e.g., Corballis, 2010; Locke, 2007).

Further studies are now needed to confirm our results. A longitudinal study including pointing tasks and the Brunet-Lézine test, along with an evaluation of handedness patterns for manipulative actions would be particularly appropriate to explain the way in which DQ for language varies for each child and to clarify its links with the development of hand preference.

\section{REFERENCES}

Baldwin, D. A., Markman, E. M., Bill, B., Desjardins, R. N., Irwin, J. M., \& Tidball, G. (1996). Infants' reliance on a social criterion for establishing word-object relations. Child Development, 67, 35-53.

Bates, E., \& Dick, F. (2002). Language, gesture and the developing brain. Developmental Psychobiology, 40, 293 310.
Bates, E., O’Connell, B., Vaid, J., Sledge, P., \& Oakes, L. (1986). Language and hand preference in early development. Developmental Neuropsychology, 2, 1-15.

Bernardis, P., Bello, A., Pettenati, P., Stefanini, S., \& Gentilucci, M. (2008). Manual actions affect vocalizations of infants. Experimental Brain Research, 184, 599-603.

Bernardis, P., \& Gentilucci, M. (2006). Speech and gesture share the same communication system. Neuropsychologia, 44, 178-190.

Blake, J., O'Rourke, P., \& Borzellino, G. (1994). Form and function in the development of pointing and reaching gestures. Infant Behavior and Development, 17, 195203.

Bonvillian, J. D., Richards, H. C., \& Dooley, T. T. (1997). Early sign language acquisition and the development of hand preference in young children. Brain \& Language, 58, 1-22.

Butterworth, G., Franco, F., McKenzie, B., Graupner, L., \& Todd, B. (2002). Dynamic aspects of visual event perception and the production of pointing by human infants. British Journal of Developmental Psychology, 20, 1-24.

Butterworth, G., \& Morissette, P. (1996). Onset of pointing and the acquisition of language in infancy. Journal of Reproductive and Infant Psychology, 14, 219-231.

Brunet, O., \& Lézine, I. (1965). Le développement psychologique de la première enfance [Psychological development in infancy]. Paris: Presses Universitaires de France.

Camaioni, L. (1997). The emergence of intentional communication in ontogeny, phylogeny and pathology. European Psychologist, 2, 216-225.

Casey, B. J., Tottenham, N., Liston, C., \& Durston, S. (2005). Imaging the developing brain: What have we learned? Trends in Cognitive Sciences, 9(3), 104-110.

Cochet, H. (2012). Development of hand preference for object-directed actions and pointing gestures: A longitudinal study between 15 and 25 months of age. Developmental Psychobiology, 54, 105-111.

Cochet, H., Jover, M., \& Vauclair, J. (2011). Hand preference for pointing gestures and bimanual manipulation around the vocabulary spurt period. Journal of Experimental Child Psychology, 110, 393-407.

Cochet, H., \& Vauclair, J. (2010a). Features of spontaneous pointing gestures in toddlers. Gesture, 10(1), 86-107.

Cochet, H., \& Vauclair, J. (2010b). Pointing gestures produced by toddlers from 15 to 30 months: Different functions, handshapes and laterality patterns. Infant Behavior and Development, 33, 432-442.

Cochet, H., \& Vauclair, J. (2010c). Pointing gesture in young children: Hand preference and language development. Gesture, 10, 129-149.

Corballis, M. C. (2003). From hand to mouth: Gesture, speech and the evolution of right-handedness. The Behavioral and Brain Sciences, 26, 199-260.

Corballis, M. C. (2010). Mirror neurons and the evolution of language. Brain \& Language, 112(1), 25-35.

Dehaene-Lambertz, G., Dehaene, S., \& Hertz-Pannier, L. (2002). Functional neuroimaging of speech perception in infants. Science, 298(5600), 2013-2015. 
Dubois, J., Hertz-Pannier, L., Cachia, A., Mangin, J. F., Le Bihan, D., \& Dehaene-Lambertz, G. (2009). Structural asymmetries in the infant language and sensori-motor networks. Cerebral Cortex, 19(2), 414-423.

Durston, S., Davidson, M. C., Tottenham, N., Galvan, A., Spicer, J., Fossella, J. A., \& Casey, B. J. (2006). A shift from diffuse to focal cortical activity with development. Developmental Science, 9(1), 1-20.

Esseily, R., Jacquet, A.-Y., \& Fagard, J. (2011). Handedness for grasping objects and pointing and the development of language in 14-month-old infants. Laterality, 16(5), 565585.

Fagard, J., \& Marks, A. (2000). Unimanual and bimanual tasks and the assessment of handedness in toddlers. Developmental Science, 3, 137-147.

Franco, F., \& Butterworth, G. (1996). Pointing and social awareness: Declaring and requesting in the second year. Journal of Child Language, 23, 307-336.

Gentilucci, M., \& Dalla Volta, R. (2007). The motor system and the relationships between speech and gesture. Gesture, 7, 159-177.

Gentilucci, M., \& Dalla Volta, R. (2008). Spoken language and arm gestures are controlled by the same motor control system. The Quarterly Journal of Experimental Psychology, 61, 944-957.

Heimann, M., Strid, K., Smith, L., Tjus, T., Ulvund, S. E., \& Meltzoff, A. N. (2006). Exploring the relation between memory, gestural communication and the emergence of language in infancy: Longitudinal study. Infant and Child Development, 15, 233-249.

Hewes, G. W. (1973). Primate communication and the gestural origin of language. Current Anthropology, 14, 5-24.

Iverson, J. M., \& Goldin-Meadow, S. (2005). Gesture paves the way for language development. Psychological Science, $16,367-371$.

Iverson, J. M., \& Thelen, E. (1999). Hand, mouth and brain: The dynamic emergence of speech and gesture. Journal of Consciousness Studies, 6, 19-40.

Jacquet, A.-Y., Esseily, R., Rider, D., \& Fagard, J. (2012). Handedness for grasping objects and declarative pointing: A longitudinal study. Developmental Psychobiology, 54(1), 36-46.

Josse, D. (1997). Brunet-Lézine Révisé: Echelle de développement psychomoteur de la première enfance [Revised Brunet-Lézine: Scale of psychomotor development in infancy]. Issy-les-Moulineaux: EAP.

Knecht, S., Dräger, B., Deppe, M., Bobe, L., Lohmann, H., Flöel, A., ... Henningsen, H. (2000). Handedness and hemispheric language dominance in healthy humans. Brain, 123, 2512-2518.

Laasko, M. L., Poikkeus, A. M., Katajamäki, J., \& Lyytinen, P. (1999). Early intentional communication as a predictor of language development in young toddlers. First Language, 19, 207-231.

Liszkowski, U., Carpenter, M., Henning, A., Striano, T., \& Tomasello, M. (2004). Twelve-month-olds point to share attention and interest. Developmental Science, 7, 297-307.
Liszkowski, U., Carpenter, M., \& Tomasello, M. (2008). Twelve-month-olds communicate helpfully and appropriately for knowledgeable and ignorant partners. Cognition, 108, 732-739.

Locke, J. L. (2007). Bimodal signaling in infancy: Motor behavior, reference, and the evolution of spoken language. Interaction Studies: Social Behaviour and Communication in Biological and Artificial Systems, 8, 159-175.

McManus, I. C., Sik, G., Cole, D. R., Mellon, A. F., Wong, J., \& Kloss, J. (1988). The development of handedness in children. British Journal of Developmental Psychology, 6, 257-273.

Meguerditchian, A., \& Vauclair, J. (2009). Contrast of hand preferences between communicative gestures and non communicative actions in baboons: Implications for the origins of hemispheric specialization for language. Brain and Language, 108, 167-174.

Meguerditchian, A., Vauclair, J., \& Hopkins, W. D. (2010). Captive chimpanzees use their right hand to communicate with each other: Implications for the origin of the cerebral substrate for language. Cortex, 46, 40-48.

Mills, D. L., Coffey-Corina, S. A., \& Neville, H. J. (1993). Language acquisition and cerebral specialization in 20month-old infants. Journal of Cognitive Neuroscience, 5, $317-334$

Mills, D. L., Plunkett, K., Prat, C., \& Schafer, G. (2005). Watching the infant brain learn words: Effects of vocabulary size and experience. Cognitive Development, 20, 1931.

Moll, H., \& Tomasello, M. (2007). How 14- and 18-montholds know what others have experienced. Developmental Psychology, 43, 309-317.

Özçaliskan, S., \& Goldin-Meadow, S. (2005). Gesture is at the cutting edge of early language development. Cognition, 96, 101-113.

Özyürek, A., Willems, R. M., Kita, S., \& Hagoort, P. (2007). On-line integration of semantic information from speech and gesture: Insights from event-related brain potentials. Journal of Cognitive Neuroscience, 19, 605-616.

Ressel, V., Wilke, M., Lidzba, K., Lutzenberger, W., \& Krägeloh-Mann, I. (2008). Increases in language lateralization in normal language as observed using magnetoencephalography. Brain and Language, 106, 167-176.

Rowe, M. L., \& Goldin-Meadow, S. (2009). Early gesture selectively predicts later language learning. Developmental Science, 12, 182-187.

Rowe, M. L., Özçaliskan, S., \& Goldin-Meadow, S. (2008). Learning words by hand: Gesture's role in predicting vocabulary development. First Language, 28, 182-199.

Taglialatela, J. P., Cantalupo, C., \& Hopkins, W. D. (2006). Gesture handedness predicts asymmetry in the chimpanzee inferior frontal gyrus. NeuroReport, 17, 923-927.

Trevarthen, C. (1996). Lateral asymmetries in infancy: Implications for the development of the hemispheres. Neuroscience and Biobehavioral Reviews, 20, 571-586.

Tomasello, M. (2008). Origins of human communication. Cambridge MA: MIT Press. 
Tomasello, M., Carpenter, M., \& Liszkowski, U. (2007). A new look at infant pointing. Child Development, 78, 705-722.

Vauclair, J., \& Imbault, J. (2009). Relationships between manual preferences for manipulative actions and for pointing gestures in infants and toddlers. Developmental Science, 12, 1060-1069.

Volterra, V., Caselli, M. C., Capirci, O., \& Pizzuto, E. (2005). Gesture and the emergence and development of language. In M. Tomasello \& D. Slobin (Eds.), Beyond naturenurture: Essays in honor of Elizabeth Bates (pp. 3-30). Mahwah, NJ: Lawrence Erlbaum Associates.
Willems, R. M., \& Hagoort, P. (2007). Neural evidence for the interplay between language, gesture and action: A review. Brain \& Language, 101, 278-289.

Xu, J., Gannon, P. J., Emmorey, K., Smith, J. F., \& Braun, A. R. (2009). Symbolic gestures and spoken language are processed by a common neural system. Proceedings of the National Academy of Sciences of United States of America, 106(49), 2066420669.

Young, A. M., Lock, A. J., \& Service, V. (1985). Infants' hand preferences for actions and gestures. Developmental Neuropsychology, 1, 17-27. 